\title{
Formação docente e inclusão escolar em um curso de Licenciatura em Educação Física
}

\author{
Khaled Omar Mohamad El Tassa* \\ Gilmar de Carvalho Cruz**
}

\section{Resumo}

A formação profissional para a docência ocupa posição de destaque em debates acadêmicos, profissionais e políticos referentes à inclusão escolar. Tem-se como objetivo do presente estudo discutir como o processo formativo realizado em um curso de Licenciatura em Educação Física trata o tema inclusão escolar, com vistas à preparação docente para a intervenção profissional em contextos educacionais inclusivos. Os resultados indicam que a Educação Física a partir de um olhar crítico sobre ela mesma, com especial atenção para os processos formativos deflagrados nas Universidades, pode contribuir para que o atendimento educacional oferecido pela escola leve em consideração a diversidade humana.

Palavras-chave: Inclusão; Formação docente; Educação Física.

* Professor doutor da Universidade Estadual do Centro-Oeste, Irati, Paraná, Brasil.

** Professor doutor da Universidade Estadual do Centro-Oeste, Irati, Paraná, Brasil. 


\section{School inclusion in teacher training course in Physical Education}

\section{Abstract}

The vocational training for teachers occupies a prominent position in academic, professional and political debates related to school inclusion. This work's objective is to discuss how the training process is conducted in an undergraduate degree in Physical Education brings the theme "school inclusion", aimed at teaching preparation for professional intervention in inclusive educational settings. Results indicate that Physical Education, based on a critical vision of itself, with special attention to the formative processes unleashed in universities, can contribute to the achievement of respect for difference and diversity in the school.

Keywords: Inclusion; Teacher education; Physical Education.

\section{Provocações iniciais}

Nos cursos de formação docente para atuação na Educação Básica, acumulamse queixas profissionais sobre a consistência da formação profissional para o magistério oferecida em cursos de nível superior. Todavia, essas queixas nem sempre repercutem nos espaços de discussão acadêmica e mais raramente ainda se transformam em críticas que colaborem no aprimoramento da articulação entre a Educação Básica e o Ensino Superior, quer para incrementar a preparação profissional, quer para robustecer a educação escolarizada oferecida na Educação Básica.

A formação docente para a Educação Básica é um dos itens presente nas discussões relacionadas à escolarização de pessoas que apresentam necessidades especiais. Esse debate reflete em políticas educacionais inclusivas, orientadas para o atendimento de alunos com necessidades especiais em ambientes regulares de ensino (BRASIL, 2011, 2010, 2009, 2008, 2004, 2001). Demandas sociais e debates acadêmicos findam por refletir em documentos como as Diretrizes Curriculares Nacionais para a formação inicial em nível superior (cursos de licenciatura, cursos de formação pedagógica para graduados e cursos de segunda licenciatura) e para a formação continuada (BRASIL, 2015), a Política Nacional de Formação de Profissionais do Magistério da Educação Básica (BRASIL, 2009) e a Política Nacional de Educação Especial na Perspectiva da Educação Inclusiva (BRASIL, 2008).

Os textos mencionados repercutem nos cursos de formação de professores à medida que exigem o aprimoramento dos cursos de Licenciatura com vistas ao atendimento de seus pressupostos. No artigo $2^{\circ}$ das Diretrizes Curriculares Nacionais para a Formação de Professores da Educação Básica (BRASIL, 2002) indica-se, naquilo que se refere à "formação para a atividade docente", que a organização curricular deve observar, entre outros aspectos, o acolhimento e o trato da diversidade 
e "o desenvolvimento de hábitos de colaboração e de trabalho em equipe". Essas Diretrizes apontam para processos de mudanças que extrapolam ordenamentos legais, reunindo-se às angústias educacionais diante dos desafios presentes em nosso sistema de ensino. A universidade, particularmente no que se refere à formação de professores, estabelece uma relação de interdependência com esse complexo e dinâmico processo.

A preparação profissional para a docência ocupa posição de destaque em debates acadêmicos, profissionais e políticos que se referem à inclusão escolar de pessoas com necessidades educacionais especiais. Ilustra esses debates no Brasil o Manifesto da Comunidade Acadêmica, direcionado à Presidenta da República e ao Ministro da Educação, solicitando "revisão da Política Nacional de Educação Inclusiva" (PETIÇÃO PÚBLICA, 2011). Importa por em relevo o que pode se chamar de raro consenso acerca da inclusão escolar de pessoas com necessidades especiais: a necessidade de preparaçáo profissional adequada para atender demandas específicas de alunos, em contextos complexos e dinâmicos como aqueles que configuram a escola. Em boa parte das discussóes e textos elaborados sobre inclusão escolar de pessoas com necessidades especiais, a formaçáo dos professores é assunto destacado.

A fim de se organizar em consonância à legislação vigente, as universidades brasileiras estão a promover reformulações curriculares em seus cursos de Licenciatura. Nesse sentido, pretende-se discutir como o processo formativo realizado em um curso de Graduação em Educação Física - área que tradicionalmente carrega consigo marcas de uma história excludente daqueles que não alcançam o preceito olímpico: citius, altius, fortius - trata o tema inclusão escolar, com vistas à preparaçáo docente para a intervenção profissional em contextos educacionais que pretendem atender quaisquer alunos, a despeito de suas mais peculiares condiçóes de aprendizagem. Para tanto, tem-se como objetivo do estudo analisar a formação docente em nível de graduação com vistas à atuação profissional em contextos educacionais inclusivos a partir de problemas práticos vivenciados no campo de estágio com o envolvimento de alunos em situação de inclusão escolar.

\section{Sobre o método}

No segundo semestre do ano letivo de 2013, constituiu-se grupo focal (GATTI, 2005; NOGUEIRA-MARTINS; BOGUS, 2004; KRUEGER, 1998; MORGAN, 1997) com 18 licenciandos do quarto ano de um curso de Educação Física, com a temática central formação profissional em contextos inclusivos. Foram três encontros, de aproximadamente duas horas cada um, com a participaçáo efetiva de 14 acadêmicos, a professora supervisora da disciplina Estágio Supervisionado, e dois moderadores pesquisadores. Duas aulas de Educação Física ministradas por dois licenciandos junto a uma turma (composta por 25 alunos) de $8^{\circ}$ ano de uma Escola Estadual de Educação Básica, por ocasião da realização do estágio curricular obrigatório, foram registradas em vídeo e serviram como provocadoras das discussóes realizadas no âmbito do grupo focal. Essas aulas retrataram a inclusão escolar de alunos com dificuldades de inserção nas aulas de Educação Física vivenciadas no cotidiano escolar. Elas constituíram textos vivos, e extremamente enriquecedores para as discussóes realizadas nos três encontros do grupo focal. A análise dos dados apoiou-se em elementos da análise de conteúdo proposta por Bardin (2008). 
Foram realizados três encontros utilizando a técnica de grupo focal, com duração de 80 a 120 minutos. As respostas e discussóes foram registradas e gravadas por intermédio de quatro gravadores digitais, tendo-se no final de cada entrevista um registro manuscrito das informaçóes importantes e um registro em áudio na íntegra. A gravaçáo foi iniciada mediante autorizaçáo dos participantes e finalizada após o encerramento da discussão. Posteriormente, os arquivos foram transcritos na íntegra, atribuindo-se a cada licenciando participante um código (P1, P2, P3, etc.), e a cada professor outro (PR1, PR2 e PR3), para evitar a sua identificação.

O grupo focal foi coordenado por dois pesquisadores, com planejamento previamente estruturado para tal finalidade. Para seu desenvolvimento foi adotada a organizaçáo em círculo. A fim de preservar a qualidade das falas de cada um dos participantes, utilizou-se para registro quatro gravadores digitais, que ficaram distribuídos em locais estratégicos para captação do áudio. As análises das aulas filmadas geraram quadros organizados a partir das respostas de cada participante às questóes relevantes por ocasião do grupo focal.

As filmagens das aulas foram realizadas pelos integrantes da equipe executora do projeto (professores pesquisadores e alunos de iniciação científica), utilizando-se filmadora digital. Todas as informações sobre objetivos, procedimentos, avaliações e questôes legais do estudo foram apresentadas ao Núcleo Regional de Educação, direção da escola, responsáveis, alunos e professores. Aqueles que optaram por participar da pesquisa assinaram um termo de consentimento livre e esclarecido.

\section{Informações construídas e discussão}

A transcrição das falas decorrentes do grupo focal e a análise das respectivas informaçóes resultaram em análises descritivas e quadros com o conjunto de respostas das participantes da pesquisa, organizados a partir de um tema disparador - relacionado à prática pedagógica em contextos educacionais inclusivos. A partir das aulas filmadas temas disparadores (inclusão/exclusão nas aulas de Educação Física e contribuição do curso de graduação na formação profissional, por exemplo), anunciados aos participantes presentes nos encontros deflagravam as discussóes. Na sequência os participantes emitiam suas opinióes reconsiderando-as, quando pertinente, em função de algum comentário de outro integrante do grupo focal. Das entrevistas coletivas no grupo focal e a partir de estrato das expressóes dos alunos organizou-se o Quadro 1, a seguir: 


\begin{tabular}{|c|c|c|}
\hline Participantes & Expressáo dos participantes & Tema de focalizaçáo \\
\hline P1 & $\begin{array}{l}\text { A gente mesmo aprendeu vivenciando... } \\
\text { Náo teve ninguém pra corrigir você... }\end{array}$ & \multirow{6}{*}{ Insatisfação com o curso } \\
\hline $\mathrm{P} 2$ & $\begin{array}{l}{[. . .] \text { a experiência que eu tive no esporte e }} \\
\text { treinamento me deu mais condição para } \\
\text { poder aplicar no estágio... }\end{array}$ & \\
\hline P6 & $\begin{array}{l}\text { Alguns }[. . .] \text { parecem que realmente não } \\
\text { sabiam o que era licenciatura... Davam } \\
\text { mais conteúdos para o bacharel... }\end{array}$ & \\
\hline P11 & $\begin{array}{l}\text { Eu entrei com um conhecimento de dança... } \\
\text { Entrei apta a dar dança... Estou saindo apta } \\
\text { para dar dança... E apenas a dança... }\end{array}$ & \\
\hline P12 & {$[\ldots]$ algumas coisas faltaram... } & \\
\hline P13 & Eu estou saindo daqui enojado. & \\
\hline P3 & [...] é lá que a gente vai ter vivências... & \multirow{6}{*}{ Relevância do Estágio } \\
\hline P4 & $\begin{array}{l}\text { No estágio é que você vai estar aprendendo } \\
\text { a ser professor. }\end{array}$ & \\
\hline P7 & $\begin{array}{l}\text { A matéria que a gente mais aproximou da } \\
\text { realidade... foi realmente o estágio mesmo... }\end{array}$ & \\
\hline P8 & $\begin{array}{l}{[. . .] \text { foi uma coisa bem... Bem estruturante }} \\
\text { pra gente... }\end{array}$ & \\
\hline P10 & $\begin{array}{l}\text { Acho que o momento mais importante } \\
\text { foi o estágio mesmo... Você tá incluso na } \\
\text { realidade mesmo... }\end{array}$ & \\
\hline P14 & $\begin{array}{l}\text { Eu também acho que a disciplina mais } \\
\text { significante pra nós foi o estágio... Porque } \\
\text { ela é a realidade... }\end{array}$ & \\
\hline P5 & $\begin{array}{l}\text { Valorizo as conversas com os próprios } \\
\text { colegas... Mas isso que faz a gente ter mais } \\
\text { participação na aula... Conversa com os } \\
\text { colegas e esse tipo de conversa com vocês... }\end{array}$ & Envolvimento \\
\hline
\end{tabular}

Ao reunir as expressões dos participantes da pesquisa é possível organizá-las em três grandes temas de focalização. Um conjunto de excertos de suas falas nos remete à ideia de insatisfação com o processo formativo realizado no curso de Licenciatura em Educação Física. Por outro lado, depreende-se também de suas falas aspectos que denotam a relevância desse mesmo processo formativo por ocasião da realização de uma de suas etapas: o estágio curricular obrigatório, ou, ainda assim denominado, estágio supervisionado. Por fim, merece destaque o apontamento que diz respeito ao envolvimento daqueles que tomam parte desse processo formativo. Nesse sentido, a organização de momentos de diálogos entre os alunos e, inclusive, com docentes da educaçâao básica e do próprio curso de licenciatura aparecem nas falas dos licenciandos como momento importante em seus processos formativos. 
Seis dos licenciandos participantes do estudo demonstraram insatisfação na realização do curso, relatando não agregar conjunto de conhecimentos que tinham expectativa ao ingressar no curso de graduação (Quadro 1). De acordo com o ponto de vista de oito dos participantes, as três disciplinas de Estágio Supervisionado constantes na grade curricular são importantes no processo de formação acadêmica. Alguns participantes do grupo focal enfatizaram a necessidade do estágio curricular obrigatório realmente representar situaçôes reais encontradas no cotidiano das escolas.

De maneira geral, as Licenciaturas ainda não estão preparadas para desempenhar a função de formar professores com uma orientação inclusiva de atuação profissional. Isso é preocupante, pois os alunos estáo sendo inseridos nas escolas e cada vez mais as salas de aula se diversificam, embora, evidentemente, não no ritmo desejado (GLAT; PLETSCH, 2004). Deparamo-nos, portanto, com uma inclusão precarizada. De acordo com o Parecer CNE/CEB no 7 de 2010, é "[...] preciso fazer da escola a instituição acolhedora, inclusiva, pois essa é uma opção 'transgressora', porque rompe com a ilusão da homogeneidade e provoca, quase sempre, uma espécie de crise de identidade institucional" (BRASIL, 2010, p. 20). Alguns licenciandos questionaram o espaço que a temática inclusão ocupa no projeto pedagógico do curso. Participantes do grupo focal expressaram que na condição de futuros professores sentem-se desprotegidos e mostraram-se preocupados ao assumir turmas de alunos com características diversas. A esse respeito, e com relação à formação profissional oferecida no curso de graduação, e à carga horária disponibilizada para direçôes em cada disciplina de estágio curricular obrigatório, (conforme normatização do Curso de Educação Física) os licenciandos (P1, P3, P5 e P6), mencionaram que:

Independente de ter deficiência ou não, eu acho que mesmo que não é só na parte da inclusão né, eu tipo nunca joguei futebol, se eu for dar futebol com o que eu aprendi na faculdade, eu não me sinto preparado, talvez eles se sintam mais preparados porque eles já praticaram futebol, então eu acho que a faculdade não prepara, mas ela da uma base, base pra você buscar esse conhecimento pra ta atendendo qualquer tipo de aluno (P1).

[...] na graduaçấo a única matéria que teve na área da inclusão, foi [...] Educação Física Adaptada, dai hoje em dia tem esse processo de inclusão que todo mundo está buscando, mas o professor que é o principal talvez não esteja sendo preparado pra isso (P3).

[...] só uma consideração incluir o que? Talvez não só a questão do aluno que tenha alguma deficiência, mas será que lá na nossa aula, no estágio, você vai ter incluir o aluno mais gordinho... isso a gente não vai ter na graduação, acredito que vai ser na vivência mesmo e náo na graduaçấo (P5).

[...] na graduação a gente não tem o preparo, a faculdade não prepara, mas ela da uma base pra você buscar o conhecimento. Eu acho que os professores, dão uma base, cabe a cada aluno professor e cada acadêmico buscar conhecimento, não só ficar naquilo que aprendeu na universidade, achando que está preparado né (PG). 
A inclusão escolar exige dos professores de Educação Física uma tarefa muito mais humilde: que sejam especialistas na arte de traduzir as diferenças que chegam até suas aulas. Nessas circunstâncias, "[...] será considerado bom professor (bom intérprete) aquele que traduz mais apropriadamente a diferença com o qual se depara, explicando, em alto e bom som, as regras que guiaram sua leitura e que tornaram válida sua interpretação" (GOMES; ALMEIDA; BRACHT, 2010, p. 11). Para Mantoan (2004) o paradigma da inclusão surge para aprimorar a educação escolar, inclusive, podemos assumir, aquela presente nos processos formativos realizados em cursos de graduação. Isso possibilita avanços a todos os alunos, com ou sem deficiência, a partir de uma pedagogia focada no educando, reconhecendo suas diferenças, explorando suas potencialidades e dando oportunidade de vivências cognitivas e sociais para todos os integrantes das instituiçôes escolares.

Estudos sobre educação inclusiva apontam várias estratégias para as escolas minimizarem as barreiras de aprendizagem e caminhar em direção à qualidade de ensino para todos os alunos (CRUZ et al., 2011; JANNUZZI, 1992). Entre essas estratégias, destacam ᄀ-se a recomendação de oferecer informaçóes e quebrar mitos e preconceitos; garantir formação permanente para todos os profissionais envolvidos no processo, com os professores assumindo a condição de protagonistas em programas de formação continuada; valorizar o professor, que é o responsável por importantes tarefas da escola; estabelecer sistemas de colaboração e/ou de cooperação, criando e/ou fortalecimento uma rede de apoio (CRUZ et al., 2011; MENDES; ALMEIDA; TOYODA, 2011).

Outro aspecto importante a ser ressaltado que colabora para educação inclusiva é a participação efetiva da comunidade escolar. Esse envolvimento coletivo, para além da especificidade do trabalho relacionado a pessoas com deficiência, por exemplo, diz respeito à formação docente em linhas mais gerais. Esse aspecto mais geral da formação docente relacionado ao envolvimento e ao trabalho em equipe pode ser observado nas recém-publicadas "Diretrizes Curriculares Nacionais para a formação inicial em nível superior (cursos de licenciatura, cursos de formação pedagógica para graduados e cursos de segunda licenciatura)" (BRASIL, 2015). Nessa mesma linha de raciocínio, também as Diretrizes Curriculares Nacionais para os Cursos de Graduação em Pedagogia (BRASIL, 2006) e Educação Física (BRASIL, 2004), a título de ilustração, aludem, com uma das habilidades docentes o trabalho em equipe. Estudos sobre a inclusão escolar têm forçado a adesão ao princípio de que os professores não devem trabalhar sozinhos, mas em equipes compostas por um grupo de pessoas cujas respostas e funçôes sejam derivadas de filosofia e objetivos mútuos (MADDUX, 1988 apud GARGIULO, 2003). Modelos de colaboração entre professores, pais e demais profissionais das escolas, que têm sido implementados para atender à diversidade, já são reconhecidos como estratégias poderosas e bem sucedidas (FEDERICO; HERROLD; VENN, 1999; WOOD, 1998). Nesse sentido, P1 reconhece que o acompanhamento da professora supervisora de campo do Estágio contribuiu para o desenvolvimento das açóes junto aos alunos e agregou saberes a todos envolvidos no processo, inclusive para a própria docente supervisora de Estágio. A esse respeito P1 relatou que: 
[...] e a nossa professora do ensino fundamental (supervisora de campo) está usando tudo que a gente fez no ensino fundamental, ela está fazendo no médio, a gente deu badminton ela criou um esporte chamado raquetebol, com os alunos, então isso difere, ganhou os alunos lá (P1).

Nos cursos de Licenciatura o tema inclusão representa uma inequívoca provocação, principalmente se ampliarmos a ideia de inclusão para além do atendimento escolar de pessoas com necessidades especiais, chegando ao espaço/tempo da preparação para a docência. Uma formação inicial de qualidade prepara os futuros professores para a complexidade e para os desafios que se colocam à construçáo de uma educação inclusiva. Ao longo da realização do grupo focal, construíram-se argumentos decorrentes das experiências adquiridas por ocasião da realização do estágio curricular obrigatório e de interlocuçóes junto aos docentes participantes desse processo. Estratégias utilizadas para a superação de algumas situações de exclusão nas aulas de Educação Física também podem ser depreendidas da vivência oportunizada no campo de estágio, conforme observa-se nos relatos de P6 abaixo:

No meu estágio também aconteceu isso, era uma atividade, com meninos e meninas juntos né... Dai eu percebi que estava meio parado... Até de ficar assistindo... Dai eu peguei e parei e comecei a colocar algumas regras... Tem que passar por todos, dai eles começavam a jogar, e, eu colocava outra regra... Agora só as meninas podem marcar o ponto... Eu acho que precisa dar esse feedback... Até as meninas estavam desmotivadas... Dai a hora que eu coloquei as regras elas se motivaram a participar porque dai elas também pegavam na bola (P6).

A formação profissional inicial tem o compromisso de dotar o futuro professor de um currículo formativo, com um suporte sólido e consistente também nos aspectos culturais. Conforme Menezes,

[...] deve, ainda, favorecer experiências reflexivas, vivência no coletivo, conduzindo à formação de maneira que permita ao estudante estabelecer relaçóes entre teoria e prática, bem como participar de processos de criação de estratégias para administrar os conteúdos de sua disciplina, sua integração com outras e a necessidade de flexibilização de que muito carece o desempenho pedagógico. (MENEZES, 2009, p. 216.).

Enfim, a formação para uma escola inclusiva privilegia a prática reflexiva, a partir da realidade do professor, pois "[...] a prática docente crítica, implicante do pensar certo, envolve o movimento dinâmico, dialético, entre o fazer e o pensar sobre o fazer" (FREIRE, 2002, p.42). Tal aprendizado, certamente tem início na formaçáo, porém outras aprendizagens seráo conhecidas na prática, em situaçóes vivenciadas, refletidas e compartilhadas no interior da escola, potencializando a inovação educativa e a formaçáo inicial e continuada. Uma formação de qualidade prepara os professores para a complexidade e para os desafios que se colocam à construçáo de uma educação inclusiva. 


\section{Considerações finais}

As informaçôes obtidas ao longo do estudo indicam contradição entre ordenamento legal e processos formativos relacionados à formação de professores para a atuação na Educação Básica no que diz respeito à preparação profissional para a docência em contextos educacionais inclusivos. Na Educação Básica, a literatura pertinente aponta para a necessidade de um envolvimento coletivo para a garantia de processos de escolarização de pessoas com necessidades educativas especiais que sejam efetivos. O mesmo pode se pensar no âmbito da formação de professores em cursos de nível superior. Se, por exemplo, uma disciplina como Libras - há pouco presente na grade curricular de cursos de licenciatura (BRASIL, 2005) - cumpre o papel de oferecer alguma ferramenta objetiva para a comunicação de docentes da Educação Básica com alunos surdos, por outro lado ela pode figurar mais como um atendimento a exigências legais sem qualquer repercussão ou significado interno, seja na Educação Básica ou na Superior.

É como se a universidade, que prepara professores para a Educação Básica, reconhecesse a existência de pessoas surdas, seguindo na ilustração anterior, apenas a partir de 2005 e se organizasse para atender a essa demanda sócio-educacional quase cinco anos após esse reconhecimento. As expressóes apresentadas pelos participantes do estudo a partir de suas experiências no campo de estágio sugerem estar relacionadas, de um lado, à particularização do assunto inclusão escolar, abordado em disciplina que não dialoga e nem é reconhecida como possuidora de interface com outras disciplinas do curso de licenciatura. De outro lado, o tardio reconhecimento da universidade de que as escolas da Educação Básica recebem alunos que no quadro das necessidades educativas especiais apresentam como uma de suas características a surdez, a título de ilustração, reforça a ideia de desencontro entre ordenamento legal, processos formativos e demandas profissionais.

Talvez uma reorganização da disciplina Educação Física Adaptada (ou alguma correlata, responsável pelo conteúdo relacionado à inclusão escolar) contribua para dar mais consistência teórico-prática ao processo formativo no que diz respeito ao desenvolvimento do trabalho pedagógico. A reduçâo das lacunas existentes entre bases de conhecimento teórico e intervenções pedagógicas pode se dar por intermédio de ampliação da carga horária destinada a vivências práticas do cotidiano escolar e/ou a implementação de uma disciplina de Estágio Supervisionado (Estágio Obrigatório) que contemple a diversidade e a inclusão escolar na grade curricular dos cursos de Licenciatura em Educação Física. Havemos de atentar para que a socializaçáo das vivências profissionais realizadas por ocasião do espaço de supervisão do Estágio não seja desperdiçadas em rotinas formalistas e burocráticas de questionável contribuição à formação profissional desejada. E o próprio Estágio Obrigatório, quem sabe, deva se tornar central em cursos que visam uma formação profissional docente consistente e coerente com as demandas socioeducacionais de seu entorno.

Em tempos de megaeventos esportivos e seus legados, cumpre náo se perder de vista a existência de eventos que em sua cotidianidade apresentam inequívoca grandiosidade. Ainda que não se caracterize como atividade econômica tão atraente, 
assim como o é o Futebol ou os Jogos Olímpicos, a formação de professores para atuação profissional na Educação Básica deixa/deixará legado social, em vida, com o qual a universidade encontra-se inexoravelmente implicada. Incluir questóes relacionadas à diferença e à diversidade humana na escola é parte desse legado que pode contar com a contribuição da Educação Física a partir de um olhar crítico sobre ela mesma, com especial atenção para os processos formativos deflagrados em seus cursos de licenciatura.

\section{Referências}

BARDIN, L. Análise de conteúdo. 4 ed. Lisboa: Ediçôes 70, 2008.

BRACHT, V.; ALMEIDA, F. Q. de; GOMES, I. M. O local da diferença: desafios à educação física escolar. Pensar a Prática, Goiânia, v. 13, n. 1, p. 115, jan./abr. 2010.

BRASIL. RESOLUÇÃO CNE/CP No 2/2015. Diretrizes Curriculares Nacionais para a Formaçáo de Professores da Educaçấo Básica. Brasília, 2015.

DECRETO No 7.611. Dispóe sobre a educaçáo especial, o atendimento educacional especializado e dá outras providências. Brasília, 2011. PARECER CNE/CEB No 7/2010. Diretrizes Curriculares Nacionais Gerais para a Educaçáo Básica. Brasília, 2010.

DECRETO No 6.755, de 29 de janeiro de 2009. Institui a Política Nacional de Formaçáo de Profissionais do Magistério da Educaçáo Básica. Brasília: DOU, 30 de janeiro de 2009.

. Ministério da Educaçấo. Política Nacional de Educaçáo Especial na Perspectiva da Educaçáo Inclusiva. Brasília, 2008.

RESOLUÇÃO CNE/CES No 1/2006. Diretrizes Curriculares Nacionais para o Curso de Graduação em Pedagogia. Brasília, 2006.

DECRETO No 5.626. Regulamenta a Lei no 10.436, de 24 de abril de 2002, que dispóe sobre a Língua Brasileira de Sinais. Brasília, 2005.

. RESOLUÇÃO CNE/CES No 7/2004. Diretrizes Curriculares Nacionais para os Cursos de Graduaçáo em Educação Física. Brasília, 2004.

Brasília, 2001

PARECER CNE/CEB No 17/2001. Diretrizes Nacionais para a Educação Especial na Educação Básica.

Resolução CNE/CEB no 4/2010. Define Diretrizes Curriculares Nacionais Gerais para a Educação Básica. Brasília: DOU, 14 de julho de 2010.

CRUZ, G. C.; et al. Formação continuada de professores inseridos em contextos educacionais inclusivos. Educar em Revista, Curitiba, Brasil, n. 42, p. 229-243, out./dez. 2011. Editora UFPR.

FEDERICO, M.; HERROLD, J.; VENN, W. Helpful tips for successful inclusion. Teaching Exceptional Children, v. 32, n. 1, p. 76-82, 1999.

FREIRE, P. Pedagogia do oprimido. 32. ed. Rio de Janeiro: Paz e Terra, 2002.

GARGIULO, R. Education on contemporary society: an introduction to exceptio $\neg$ nality. Thomson Learning: United Station, 2003.

GATTI, B. A. Grupo focal na pesquisa em ciências sociais e humanas. Brasília: Líber Livro Editora, 2005.

GLAT, R.; PLETSCH, M. D. O papel da universidade frente às políticas públicas para educação inclusiva. Revista Benjamin Constant, Rio de Janeiro, p. 3-8, 2004.

JANNUZZI, G. A luta pela educaçáo do deficiente mental no Brasil. Campinas: Editores Associados, 1992. KRUEGER, R. Analyzing \& reporting focus group results. Thousand Oaks, California: Sage Publications, 1998.

MANTOAN, M. T. E. Caminhos Pedagógicos da Educação Inclusiva. In: GAIO, R.; MENEGHETTI, R. G. K. Caminhos Pedagógicos da Educaçấo Especial. Petrópolis: Vozes, 2004. 
MENDES, E. G.; ALMEIDA, M. A.; TOYODA, C. Y. Inclusão escolar pela via da colaboração entre educaçâo especial e educação regular. Educar em Revista, Curitiba, Brasil, n. 41, p. 81-93, jul./set. 2011. Editora UFPR. MENEZES, M. A. Currículo, formação e inclusão: alguns implicadores. In: FELDMANN, M. G. (Org.). Formaçáo de professores na contemporaneidade. São Paulo: Editora Senac, 2009.

MORGAN, D. Focus groups as qualitative research. 2.ed. Thousand Oaks. Califórnia: Sage Publications, 1997.

NOGUEIRA MARTINS, M. C. F.; BOGUS, C. M. Consideraçốes sobre a metodologia qualitativa como recurso para o estudo das ações de humanização em saúde. Saúde e Sociedade, v. 13, n. 3, p. 44-57, 2004.

PETIÇÃO PÚBLICA. Manifesto da comunidade acadêmica pela revisáo da Política Nacional de Educaçáo Inclusiva, 2011. Disponível em <http://www.peticaopublica.com.br/PeticaoVer.aspx?pi=P2011N11492>. Acesso em: 8 jul. 2011.

WOOD, M. Whose job is it anyway? Educational roles in inclusion. Exceptional Children, v. 64, n. 2, p. 181-195, 1998.

\section{Correspondência}

Khaled Omar Mohamad El Tassa - Universidade Estadual do Centro-Oeste - UNICENTRO. Campus de Irati. Departamento de Educação Física. PR 153, Km 7, Riozinho. CEP 84500-000. Irati, Paraná. Brasil.

E-mail: khaledunicentro@hotmail.com - gilmailcruz@gmail.com

Recebido em 20 de junho de 2015

Aprovado em 08 de setembro de 2015 